Одоев О.С

\title{
К ИСТОРИИ ВОПРОСА О КОНСТРУИРОВАНИИ СОСТАВОВ ПРЕСТУПЛЕНИЙ С ИСПОЛЬЗОВАНИЕМ АДМИНИСТРАТИВНОЙ ПРЕЮДИЦИИ
}

\begin{abstract}
Аннотация: Предметом настоящей статьи является конструирование составов преступлений при помощи административной преюдиции. Сущуность этого способа конструирования заключается в том, что административный проступок, неоднократно совершенный одним и тем же лицом в установленный законом срок "трансформируется" в уголовно наказуемое деяние. В статье рассматривается исторический аспект названного способа конструирования: вопросы, связанные с тем, при каких условиях он зародился и получил свое дальнейшее развитие в рамках конкретных юридических структур. При подговки статьи автором были использованы различные методы исследования, включая такие как сравнительно-исторический, историко-правовой и дедуктивный В представленной статье автором проводится анализ процессов генезиса и эволюичи конструирования составов преступлений с использованием административной преюдиции. Рассматриваются сложивщиеся в юридической теории подходьл к восприятию природы происхождения административной преюдиции в уголовном праве. Приводятся аргумента, свидетельствующие об упречности подхода, суть которого заключается в том, что у составов преступлений с административной преюдицией имелись дореволючионные прототипы. Также в рамках статьи делается предположение о том, что нормы, содержащие составы преступлений с административной преюдицией, впервые получили свое закрепление в докодификационный период развития отечественного уголовного законодательства. Дается краткая характеристика отдельным составам преступлений с административной преюдицией, имевшим место в уголовном законодательстве советского периода.
\end{abstract}

Ключевые слова: Административная преюдиция, преступление, правонарушение, состав преступления, юридическое конструирование, история уголовного законодательства, история административной преюдиции, налоговые преступления, административное законодательство, советское уголовное законодательство.

Abstract: The subject of this research is construction of the elements of crime using administrative prejudice. The essence of this method of construction consists in the fact that an administrative offense that has been committed by the same individual within a legally established period of time is being "transformed" into a criminal offense. The article examines the historical aspect of the aforementioned means of structuring: questions pertaining to the conditions under which it originated and saw its further development within the framework of specific legal structures. The author conducts the analysis of the processes of origin and evolution of the structuring of the elements of crime using administrative prejudice. The examination includes the current approaches within the legal theory towards perception of the nature of origin of the administrative prejudice in criminal law. The author offers arguments that testify to the imperfectness of the approach, the essence of which lies in the fact that the elements of crimes with administrative prejudice had pre-revolutionary prototypes. The author also makes presuppositions that the norms containing elements of a crime with administrative prejudice have received their first official establishment during the pre-codification period of development of Russian criminal law.

Keywords: History of administrative prejudice, history of criminal law, legal construction, element of crime, offense, crime, administrative prejudice, tax crimes, administrative law, Soviet criminal law.

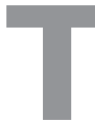
вердой поступью в российское уголовное законодательство входят нормы, содержащие составы преступлений с административной преюдицией. Обеспечивая взаимосвязь предписаний различных отраслей права, эти нормы предполагают привлечение к уголовной ответственности только в случаях «... если деяние совершено в течение определенного периода времени после наложения одного или двух административных взысканий за такое же правонарушение» [22, с. 69-79].

Упомянутые выше нормы, не являясь чемто принципиально новым для нашей правовой системы, насчитывают длительную историю 
своего возникновения, становления и развития. Однако в юридической доктрине, как нам думается, вопросы генезиса и эволюции названных норм не получили должного освещения. В отечественных научных и учебных публикациях подобные вопросы, как правило, рассматриваются либо попутно с проблемой допустимости административной преюдиции в уголовном праве [23], либо при иллюстрации на примере истории правовых норм, устанавливающих ответственность за конкретные виды преступлений [24].

Анализ литературы, в той или иной степени посвященной затронутой проблематике, позволяет выделить два подхода по восприятию процессов зарождения и развития названных выше норм.

В максимально упрощенном виде первый подход можно представить так, что его сторонники (В.П. Малков, В.И. Колосова, Н.Ю. Скрипченко и др.) рассматривают изучаемые нормы как уникальное порождение сочиалистической юридической (уголовно-правовой) техники, как «сугубо советскую выдумку» [18]. Другими словами, на взгляд этих ученых, использование административной преюдиции для конструирования составов преступлений суть изобретение исключительно советского законодателя.

Сторонники второго подхода (А.Г. Безверхов, Е.С. Изюмова, И.А. Попова и др.), напротив, изучаемые нормы представляют как результат правовой преемственности досоветских юридических инструментов. Иначе говоря, они считают, что построение составов преступлений при помощи административной преюдиции не было «придумано» советским законодателем. По их мнению, прообразы указанного способа конструирования составов преступлений содержались еще в российском законодательстве дореволюционного периода.

Изложенная дискуссия обладает теоретическим (если не сказать, методолого-правовым) характером, однако ее разрешение имеет не меньшее прикладное значение. Можно предположить, что юристы, признавая исключительно советское происхождение норм, содержащих составы преступлений с административной преюдицией, вольно или невольно отрицают их приемлемость для современных несоциалистических уголовно-правовых систем. И наоборот, наличие у названных норм дореволюционных прототипов как бы презюмирует их «универ- сальность» и актуальность для любой юридической системы.

В связи с указанным необходимо обратиться к доводам ученых, усматривающих дореволюционные «корни» уголовно-правовых норм, содержащих составы преступлений с административной преюдицией.

Так, воззрения на данные нормы, как на «вторичный продукт» по отношению к предписаниям досоветского права прослеживаются в работе, например, М.Н. Урды. Ученый, применительно к проблеме уголовной ответственности за незаконное предпринимательство, пишет: «...Административная преюдиция не является чем-то принципиально новым для отечественного законодательства. Ее зачатки имелись еще в законодательстве царской России» [17, с. 292]. Эти зачатки правовед усматривает в предписании, отраженном санкцией ст. 1368 Уложения о наказаниях уголовных и исправительных 1845 г. (в ред. 1885 г.). В силу действия этого предписания за нарушение ремесленных постановлений во второй и третий раз виновному грозило наказание в виде денежного штрафа в сумме в два раза превышающей максимальный размер штрафа, предусмотренного за совершение аналогичного деяния в первый раз. В случае повторения идентичного правонарушения в четвертый и более раз, санкция представленной статьи предусматривала наказание в виде тюремного заключения на срок от четырех до восьми месяцев [15, с. 548].

Таким образом, М.Н. Урда находит прообраз составов преступлений с административной преюдицией в нормах статей Особенной части Уложения 1845 г., регулирующих градацию суровости назначаемого лицу наказания в зависимости от количества совершенных им тождественных преступлений. Схожей точки зрения придерживается А.Г. Безверхов [3, c. 46]. По его мнению, указанные выше прототипы содержались в санкциях отдельных статей Особенной части Уложения 1845 г., обеспечивающих постепенное усиление назначаемого виновному наказания в ситуациях совершения им второго, третьего и последующего тождественных преступлений.

Собственно говоря, изложенная позиция доминирует в среде криминалистов, ратующих за дореволюционную природу происхождения исследуемых юридических норм. Она (позиция), отличаясь своей оригинальностью, безусловно, 
заслуживает внимания со стороны научной общественности. Вместе с тем назвать ее до конца обоснованной едва ли возможно, прежде всего, потому, что она не дает ответов на два важных, как нам думается, вопроса.

Первый вопрос можно поставить следующим образом: почему прообразы составов преступлений с административной преюдицией проявили себя именно в нормах Уложения 1845 г.? Ведь хорошо известно, что предписания об обязательном усилении наказания за многократное совершение ряда тождественных преступлений знакомо отечественному законодательству, как минимум, с конца XIVв. Так, ст. 5 Двинской уставной грамоты (1397 г.) применительно к множественности татьбы предписывала: «...А татя впервые продатипротиву поличного; а вдругие уличат, продадут его не жалуя; а уличат в третьи, иноповесити; а татя всякого пятнити» [12, с. 162-163]. Можно ли усмотреть прообраз современных уголовно-правовых норм, содержащих составы с административной преюдицией, в воспроизведенном законоположении? Вопрос риторический.

Во-вторых, называя заключенные в санкциях статей Особенной части Уложения 1845 г. предписания об обязательном усилении назначаемого виновному наказания при совершении им нескольких тождественных преступлений прообразами составов преступлений с административной преюдицией, ученые, тем самым, отождествляют последние с правилами назначения наказания при специальном рецидиве преступлений. Иначе говоря, не вполне понятно, правила назначения наказания при специальном рецидиве преступлений представляют собой прототип составов преступлений с административной преюдицией? Если нет, то по каким основаниям возможно произвести их различение? Если да, то снова встает первый вопрос, поскольку упомянутые правила присутствовали в правовых источниках намного раньше Уложения 1845 г.

Как бы то ни было, но вопрос о прототипах уголовно-правовых норм, содержащих составы преступлений с административной преюдицией, остается в науке на сегодня открытым.

Несколько иначе историко-аналитическое направление теории уголовного права подходит к вопросу о времени появления самих вышеуказанных норм. В частности, достаточно распространено мнение о том, что первые такие нормы были закреплены положениями Уголовного кодекса РСФСР 1922 г. [22, с.70].

С нашей точки зрения, составы преступлений с административной преюдицией можно обнаружить несколько раньше - в предписаниях первых декретов, изданных советским руководством. Так, например, п. 4 Декрета СНК от 9 августа 1921 г. «О продаже виноградных, плодово-ягодных и изюмных вин» устанавливал: «...нарушение... правил оптовой и розничной торговли вином карается в первый раз в порядке, установленном декретом... «Об административных взысканиях».... Повторное нарушение этих правил карается по суду лишением свободы или принудительными работами без лишения свободы с воспрещением торговли вином на определенный срок либо без срока» [28].

Учитывая изложенное, мы солидарны с В.П. Малковым в том, что административная преюдиция уже в первые годы советской власти использовалась в качестве криминализации отдельных правонарушений [11, с. 182].

Если говорить о кодифицированном законодательстве, то впервые состав преступления с административной преюдицией нашел свое закрепление в рамках ст. 79 УК РСФСР 1922 г. Согласно последней, «...неплатеж отдельными гражданами в срок или отказ от платежа налогов, денежных или натуральных, от выполнения повинностей или производства работ, имеющих общегосударственное значение, карается - в первый раз административными взысканиями, налагаемыми...в пределах, законом определённых. Повторный и упорный неплатеж или отказ от исполнения работ или повинностей, или иные действия, устанавливающие злостность неплательщиков, лишением свободы или принудительными работами на срок не ниже шести месяцев или конфискацией всего или части имущества...» [27].

Нужно сказать, что в то время приведенная норма обладала значительной степенью эффективности, о чем свидетельствуют данные статистики, отражающие существенное снижение количества лиц, совершивших тождественное деяние после наложения мер административного воздействия. Так, по данным на 10 ноября 1922 г. количество лиц, подвергнутых административному взысканию за неплатеж налогов, составляло 14027, тогда как лиц, совершивших аналогичное правонарушение повторно 827 [9, с. 110]. 
Судя по всему, конструкция административной преюдиции рассматривалась законодателем тех лет как удачный способ криминализации противоправных деяний, совершаемых в сфере налогов и сборов. В частности, еще одно деяние в сфере налогообложения, опосредованное административной преюдицией, было криминализовано Декретом ВЦИК и СНК от 15 декабря 1924 г. «Об изменении статьи 139-а Уголовного кодекса РСФСР». Данным Декретом ст. 139-а УК РСФСР 1922 г. излагалась следующим образом: «...Изготовление, продажа, скупка и хранение с целью сбыта, а равно пользование продуктами и изделиями, обложенными акцизным сбором... карается административным взысканием....В случае же причиненного государству более значительного ущерба или повторного совершения, нарушение установленных акцизных правил карается штрафом до тысячи рублей и принудительными работами или лишением свободы на срок до одного года с конфискацией предметов, продуктов и орудий производств» [26].

Итак, в первом советском Уголовном кодекce, административная преюдиция использовалась по преимуществу как конструктивный элемент составов налоговых преступлений. Сложившееся положение объяснимо, повидимому, общими тенденциями уголовной политики времен НЭПа. С одной стороны, предварительное назначение наказания в административном порядке было нацелено на предупреждение налоговой преступности. С другой же, усложнение процедуры привлечения к наиболее строгому виду ответственности снизило уголовно-правовые риски сельских хозяев, вследствие чего явилось стимулом для развития сельскохозяйственного предпринимательства.

Уголовный кодекс РСФСР 1926 г. органично впитал закономерности, присущие уголовноправовым нормам, содержащим составы преступлений с административной преюдицией, расширив их количество до пяти (ст. ст. 96, 112, 158, ч. 2 ст. 238, ст. 239).

Сопоставимое количество составов содержалось и в уголовных законодательствах союзных республик. Последнее в исследуемой части, к слову сказать, во всех республиках развивалось «в унисон». К примеру, п. «а»ст. 93 УК Белорусской ССР 1928 г. устанавливал наказание за неплатеж гражданами налогов или сборов при наличии реальной возможности оплатить налог или сбор и если к лицу были применены принудительные меры взыскания в административном порядке [25]. Очевидно, что эта норма полностью повторяла положения ст. 79 УК РСФСР 1922 г.

Таким образом, нормы, описывающе составы преступлений с административной преюдицией, применялись на практике на всей территории Союза ССР вплоть до конца 50-х годов XX в. Этот этап в жизни страны связан с изменениями социального, политического и, как следствие, правового характера. Последние сыграли определяющее значение в принятии Основ уголовного законодательства 1958 г., а вслед за ними и уголовных кодексов республик в составе СССР.

В Уголовном кодексе РСФСР 1960 г. (далее - УК РСФСР 1960 г.) количество изучаемых уголовно-правовых норм увеличилось в четыре раза и на момент утраты названным нормативным актом своей юридической силы достигло 24 (ст. ст. $133^{1}, 133^{2}, 152^{2}, 156,156^{4}, 156^{5}, 156^{6}, 162$, $162^{9}, 162^{1}, 162^{10}, 166,166^{1}, 167^{2}, 175^{1}, 188^{4}, 197,197^{1}$, $\left.198^{1}, 200^{1}, 208^{1}, 224^{3}, 225^{1}, 230^{1}\right)$. Для сравнения, в УК Азербайджанской ССР 1960 г. количества рассматриваемых норм увеличилось в три раза и составило 18 [7, с. 68].

Конец ХХв. ознаменовал собой наступление нового этапа в жизни мирового сообщества, инспирированного процессами крушения «социалистического лагеря». Так, с распадом Союза ССР и образованием суверенных государств сформировалась новая система идей, закладываемых в основу противодействия преступности. В этом отношении абсолютно иную позицию по ряду принципиальных уголовно-правовых и криминологических вопросов заняли законодатели государств постсоветского пространства. В частности, при принятии новых уголовных законов постоюзных стран качественному пересмотру подверглись институты соучастия в преступлении, назначения и освобождения от наказания и уголовной ответственности, множественности преступлений и др.

Не обошли реформы и уголовно-правовые нормы, содержащие составы преступлений с административной преюдицией. В частности, в отдельных постсоветских республиках результатом реформ явилась конкретизация административной преюдиции и расширение количества составов, опосредованных данным признаком. Подобное регулирование, как правило, объяснялось необходимостью профи- 
лактики нетяжких преступлений, количество которых в конце 80-х гг. ХХ в. существенно выросло. В других государствах бывшего СССР результатом преобразований, напротив, явились либо полной отказ от названных норм, либо крайнее сужение сферы их применения. В качестве основного аргумента в пользу такого решения приводилось положение о том, что использование административной преюдиции в уголовном праве противоречит базовым положениям новых конституций суверенных стран. Например, Е.В. Ямашева в этой связи отмечает: «Основным аргументом в пользу отказа от названного института стал аргумент, согласно которому наличие административной преюдиции в нормах уголовного закона противоречит конституционному принципу о том, что никто не может быть повторно осужден за одно и то же правонарушение...» [22, с. 70].

В числе государств, где законодатель отказался от уголовно-правовых норм, со- держащих составы преступлений с административной преюдицией, оказалась и Россия. Так, в первоначальной редакции Уголовного кодекса РФ 1996 г. отсутствовали названные нормы, однако начиная с 2009 г. такие нормы активно (если не сказать, - агрессивно) входят в отечественный арсенал средств уголовноправового воздействия. Вместе с тем нужно осознавать, что без системного осмысления истории вопроса деятельность по искусственному насаждению каких бы то ни было уголовно-правовых регуляторов обречена на провал. Поэтому для выработки рекомендаций по предупреждению законотворческих и правоприменительных ошибок в рассмотренной сфере представляется необходимым дальнейшее проведение научных изысканий, направленных на теоретическое изучение генезиса и эволюции уголовно-правовых норм, содержащих составы преступлений с административной преюдицией.

\section{Библиография:}

1. Артамонова М.А. Некоторые вопросы ответственности за экологические правонарушения по уголовному и административному советскому законодательству // Вестник Самарской гуманитарной академии. 2013. № 1(13). С. 44-52.

2. Бабаев В.К. Советское право как логическая система. М.: РИО Акад. МВД СССР, 1978. 212 с.

3. Безверхов А.Г. Административная преюдициальность в уголовном законодательстве России: истоки, реалии, перспективы // Вестник Самарской гуманитарной академии. 2011. № 2(10). С. 39-51.

4. Бобрович П.П. Административная преюдиция в уголовном праве // Библиотека криминалиста. 2013. № 2(7). С. 46-50.

5. Бытко Ю.И. Учение о рецидиве преступлений в российском уголовном праве: история и современность: дисс. док. юрид. наук. Саратов, 1998. 303 с.

6. Иванчин А.В. Концептуальные основы конструирования состава преступления: дисс. док. юрид. наук. Ярославль, 2014. 462 с.

7. Караев Т.Э. Повторность преступлений. М.: Юридическая литература. 1983. 104 с.

8. Колосова В.И. Административная преюдиция как средство предупреждения преступлений и совершенствования уголовного законодательства // Вестник Нижегородского университета им. Н.И. Лобачевского. 2011. № 5. С. 246-254.

9. Кучеров И.И. Налоги и криминал. Историко-правовой анализ. М., 2000. 351 с.

10. Майорова Е.И. Неоднократность преступлений по уголовному праву: дисс. канд. юрид. наук. М., 1999. 143 с.

11. Малков В.П. Неоднократность правонарушения и административная преюдиция как средства криминализации и декриминализации содеянного в российском уголовном праве // Библиотека криминалиста. 2013. № 2(7). 2013. С. 179-187.

12. Памятники русского права / Под ред. Л.В. Черепнина. Вып. 3. М.: Гос. изд-во юридической лит-ры, 1955.529 с.

13. Попова И.А. История развития административной преюдиции как обязательного признака некоторых составов преступлений // Уголовное право. Стратегия развития в XXI веке. Материалы XII Международной научно-практической конференции (29-30 января 2015 г.). М.: РГ-Пресс. 2015. С. 92-95.

14. Сборник документов по истории уголовного законодательства 1917-1952 гг. / Под ред. И.Т. Голякова. М.: Государственное издательство юридической литературы. 463 с.

15. Таганцев Н.С. Уложение о наказаниях уголовных и исправительных 1885 года. СПб., 1892.796 с.

16. Уголовный кодекс Белорусской ССР. М.: Юридическое издательство НКЮ, 1944. С. 76.

17. Урда М.Н. Социально-политическая обусловленность уголовной ответственности за незаконное предпринимательство // Актуальные проблемы российского права. 2010. № 3. С. 291-304.

18. Хавронюк Н.И. Административная преюдиция и институт рецидива с точки зрения уголовного права европейских стран [Электронный ресурс] URL: http://pravo.zakon.kz/190761-administrativnaja-prejudicija-i. html (дата обращения: 20 апреля 2015 г.) 
19. Чибизов А.В. К вопросу об административной преюдиции в делах о жестоком обращении с животными по уголовному законодательству РСФСР 1960 г. // Вестник Тамбовского университета. Серия Гуманитарные науки. 2011. № 7(99). С. 248-251.

20. Шкредова Э.Г. Множественность преступлений (исторический аспект). М.: Юрлитинформ, 2011.184 с.

21. Шкредова Э.Г. Совокупность преступлений по уголовному законодательству и доктрине второй половины XIX в. // Государство и право. 2008. № 8. С. 64-68.

22. Ямашева Е.В. К вопросу о восстановлении института административной преюдиции // Журнал российского права. 2009. № 10. С. 69-79.

23. Безверхов А.Г. Административная преюдициальность в уголовном законодательстве России: истоки, реалии, перспективы // Вестник Самарской гуманитарной академии. 2011. № 2(10). С. 39-51; Бобрович П.П. Административная преюдиция в уголовном праве // Библиотека криминалиста. 2013. № 2(7). С. 46-50; Иванчин А.В. Концептуальные основы конструирования состава преступления: дисс. док. юрид. наук. Ярославль, 2014. С. 313-329; Малков В.П. Неоднократность правонарушения и административная преюдиция как средства криминализации и декриминализации содеянного в российском уголовном праве // Библиотека криминалиста. 2013. № 2(7). С. 179-187 и др.

24. Артамонова М.А. Некоторые вопросы ответственности за экологические правонарушения по уголовному и административному советскому законодательству // Вестник Самарской гуманитарной академии. 2013. № 1(13). С. 44-52; Чибизов А.В. К вопросу об административной преюдиции в делах о жестоком обращении с животными по уголовному законодательству РСФСР 1960 г. // Вестник Тамбовского университета. Серия Гуманитарные науки. 2011. № 7(99). С. 248-251 и др.

25. Уголовный кодекс Белорусской ССР. М.: Юридическое издательство НКЮ, 1944. С. 76.

26. Известия ЦИК СССР и ВЦИК от 21 января 1925 г. № 17.

27. Сборник документов по истории уголовного законодательства 1917-1952 гг. / Под ред. И.Т. Голякова. М.: Государственное издательство юридической литературы. С. 125-126.

28. Собрание узаконений и распоряжений правительства. 1921. № 68. Ст. 543.

\section{References (transliterated):}

1. Artamonova M.A. Nekotorye voprosy otvetstvennosti za ekologicheskie pravonarusheniya po ugolovnomu i administrativnomu sovetskomu zakonodatel’stvu // Vestnik Samarskoi gumanitarnoi akademii. 2013. № 1(13). S. 44-52.

2. Babaev V.K. Sovetskoe pravo kak logicheskaya sistema. M.: RIO Akad. MVD SSSR, 1978. 212 s.

3. Bezverkhov A.G. Administrativnaya preyuditsial'nost'v ugolovnom zakonodatel'stve Rossii: istoki, realii, perspektivy // Vestnik Samarskoi gumanitarnoi akademii. 2011. № 2(10). S. 39-51.

4. Bobrovich P.P. Administrativnaya preyuditsiya v ugolovnom prave // Biblioteka kriminalista. 2013. № 2(7). S. 46-50.

5. Bytko Yu.I. Uchenie o retsidive prestuplenii v rossiiskom ugolovnom prave: istoriya i sovremennost': diss. dok. yurid. nauk. Saratov, 1998. 303 s.

6. Ivanchin A.V. Kontseptual'nye osnovy konstruirovaniya sostava prestupleniya: diss. dok. yurid. nauk. Yaroslavl', 2014. 462 s.

7. Karaev T.E. Povtornost' prestuplenii. M.: Yuridicheskaya literatura. 1983. 104 s.

8. Kolosova V.I. Administrativnaya preyuditsiya kak sredstvo preduprezhdeniya prestuplenii i sovershenstvovaniya ugolovnogo zakonodatel'stva // Vestnik Nizhegorodskogo universiteta im. N.I. Lobachevskogo. 2011. № 5. S. 246-254.

9. Kucherov I.I. Nalogi i kriminal. Istoriko-pravovoi analiz. M., 2000. $351 \mathrm{s.}$

10. Maiorova E.I. Neodnokratnost' prestuplenii po ugolovnomu pravu: diss. kand. yurid. nauk. M., 1999.143 s.

11. Malkov V.P. Neodnokratnost' pravonarusheniya i administrativnaya preyuditsiya kak sredstva kriminalizatsii i dekriminalizatsii sodeyannogo v rossiiskom ugolovnom prave // Biblioteka kriminalista. 2013. № 2(7). 2013. S. 179-187.

12. Popova I.A. Istoriya razvitiya administrativnoi preyuditsii kak obyazatel'nogo priznaka nekotorykh sostavov prestuplenii // Ugolovnoe pravo. Strategiya razvitiya v XXI veke. Materialy XII Mezhdunarodnoi nauchnoprakticheskoi konferentsii (29-30 yanvarya 2015 g.). M.: RG-Press. 2015. S. 92-95.

13. Tagantsev N.S. Ulozhenie o nakazaniyakh ugolovnykh i ispravitel'nykh 1885 goda. SPb., $1892.796 \mathrm{~s}$.

14. Urda M.N. Sotsial'no-politicheskaya obuslovlennost' ugolovnoi otvetstvennosti za nezakonnoe predprinimatel'stvo // Aktual'nye problemy rossiiskogo prava. 2010. № 3. S. 291-304.

15. Khavronyuk N.I. Administrativnaya preyuditsiya i institut retsidiva s tochki zreniya ugolovnogo prava evropeiskikh stran [Elektronnyi resurs] URL: http://pravo.zakon.kz/190761-administrativnaja-prejudicija-i.html (data obrashcheniya: 20 aprelya 2015 g.)

16. Chibizov A.V. K voprosu ob administrativnoi preyuditsii v delakh o zhestokom obrashchenii s zhivotnymi po ugolovnomu zakonodatel'stvu RSFSR 1960 g. // Vestnik Tambovskogo universiteta. Seriya Gumanitarnye nauki. 2011. № 7(99). S. 248-251.

17. Shkredova E.G. Mnozhestvennost' prestuplenii (istoricheskii aspekt). M.: Yurlitinform, 2011.184 s. 
DOI: $10.7256 / 1811-9018.2016 .6 .19325$

При цитировании этой статьи сноска на doі обязательна

Право и политика $6(198) \cdot 2016$

18. Shkredova E.G. Sovokupnost' prestuplenii po ugolovnomu zakonodatel'stvu i doktrine vtoroi poloviny XIX v. // Gosudarstvo i pravo. 2008. № 8. S. 64-68.

19. Yamasheva E.V. K voprosu o vosstanovlenii instituta administrativnoi preyuditsii // Zhurnal rossiiskogo prava. 2009. № 10. S. 69-79.

20. Bezverkhov A.G. Administrativnaya preyuditsial'nost' v ugolovnom zakonodatel'stve Rossii: istoki, realii, perspektivy // Vestnik Samarskoi gumanitarnoi akademii. 2011. № 2(10). S. 39-51; Bobrovich P.P. Administrativnaya preyuditsiya v ugolovnom prave// Biblioteka kriminalista. 2013. № 2(7). S. 46-50; Ivanchin A.V. Kontseptual'nye osnovy konstruirovaniya sostava prestupleniya: diss. dok. yurid. nauk. Yaroslavl', 2014. S. 313-329; Malkov V.P. Neodnokratnost' pravonarusheniya i administrativnaya preyuditsiya kak sredstva kriminalizatsii i dekriminalizatsii sodeyannogo v rossiiskom ugolovnom prave// Biblioteka kriminalista. 2013. № 2(7). S. 179-187 i dr.

21. Artamonova M.A. Nekotorye voprosy otvetstvennosti za ekologicheskie pravonarusheniya po ugolovnomu i administrativnomu sovetskomu zakonodatel'stvu // Vestnik Samarskoi gumanitarnoi akademii. 2013. № 1(13). S. 44-52; Chibizov A.V. K voprosu ob administrativnoi preyuditsii v delakh o zhestokom obrashchenii s zhivotnymi po ugolovnomu zakonodatel'stvu RSFSR 1960 g. // Vestnik Tambovskogo universiteta. Seriya Gumanitarnye nauki. 2011. № 7(99). S. 248-251 i dr. 